\title{
Historical analysis of strategies for assimilation and identity maintenance in dispersed groups of overseas Hungarians and their relevance regarding national policy planning
}

\section{János Tóth ¥}

‡ Kodolányi János University of Applied Sciences, Budapest, Hungary

\section{Executive summary}

Small grant proposal for the period between August 1, 2015 - December 31, 2015 of the Kelemen Mikes Program; for collecting the legacy of the Hungarian diaspora from documents of libraries and archives, and for the historical study of these communities.

\section{Keywords}

Diaspora Research, Hungarian Diaspora, National Identity, National Policy Planning

\section{State of the art and preliminary work}

\section{Presentation of the problem}

In recent years, the inspection of strategies for identity maintenance concerning dispersed groups of Hungarians living overseas, especially in developed Western democracies, as 
well as the inspection of factors aiding or obstructing the implementation of these strategies, has gained immense importance. Programs operated within the framework of the Hungarian Diaspora Council, the reorganized State Secretariat for National Policy, and the Hungarian Register are excellent examples to show that the Hungarian government has placed great emphasis on the reinforcement of the Hungarian identity of individuals being part of the Hungarian diaspora, the assistance in establishing their communication with the homeland, and informing the members of the diaspora. The circumstances mentioned above make it necessary that the government base their supportive diaspora policy, which has been repeatedly emphasized during the past years, on the current economic, cultural, religious and other realities of the Hungarian diaspora, while also taking into consideration relevant experiences from past diaspora policy processes. It is evident that the research required for achieving all of the above has to be based on empirical data and primary resources; the present research plan serves as the basis for such research.

\section{Objectives, Concept and Approach}

\section{Research Objectives}

The general goal of the research is to identify the challenges - based on historical experiences - that are relevant to the preservation of the national identity of dispersed groups of overseas Hungarians, as well as to present specific and functional national policy ideas based on the results of the research. This is planned to be achieved through the following three main objectives:

- Tematic analysis (especially focusing on identity) of the legacy of first and further generations of dispersed groups of Hungarians in given countries in libraries and archives as well as the circumstances of these documents' origins.

- Getting to know the experiences and decisions (micro-narratives) of the Hungarian diaspora that directly led to the immigration of its members and those that influenced their Hungarian identity in the specific countries through performing individual interviews.

- Making the research material (gathered throughout the accomplishment of the previous two objectives) available open access, in the form of a structured, searchable database.

\section{The theoretical framework of the research}

The conceptualization of Hungarian diaspora

In order to define the concept of the Hungarian diaspora, and to narrow the analyzed data down, I have used the definitive characteristics of diaspora communities specified by Safran (1991): 83-84. Based on the mentioned resource, I consider the following communities to be part of the Hungarian diaspora: 
a) the members of which (or their respective ancestors) had migrated from Hungary to relatively distant, peripheral regions (or the surrounding areas of the Carpathian Basin with Hungarian residents) either directly or via "transit countries",

b) the members of which possess memories and genuine stories from Hungary or they share an inherited collective memory regarding their home country,

c) the members of which experience a gap between themselves and the host society; they feel like they are not fully accepted into the new society they live in as "guests", and also, they believe that their complete social acceptance is not achievable,

d) the members of which consider Hungary to be the ideal home, where they plan to return providing they have the required conditions, and they also raise their descendants in a similar vein,

e) that has a collective commitment towards Hungary,

f) the members of which are connected to Hungary in a way and they also express empathy towards Hungary and those living in Hungary.

The reason for this choice is that we would like to release the diaspora from its victim paradigm (Cohen 2008), however, at the moment, we do not deem it beneficial to have a broad concept, based on which, any type of spatial diffusion could qualify as diaspora. For this reason, I have chosen a method of definition that includes the image of the homeland, the strength of relations to the homeland as well as the emphasis on the foreignness of the current environment.

\section{The conceptualization of identity}

When it comes to 'identity' in the study, mainly the idea of social identity and more precisely, national identity is being analyzed, i.e., we are studying a not necessarily perceptible self-image originating from knowledge and information gathered as a diasporic Hungarian individual, along with the collective superstitions, individual values, and emotional priorities regarding the diaspora. At the same time, this type of identity is regarded to be subject to effects of the majority society and individual coping strategies (as well as to other effects deriving from the available data), i.e. the concept of this identity is considered volatile rather than permanent. The study is focusing on effects that can alter this volatility in either way (towards assimilation or towards the preservation of a strong, appropriate Hungarian identity), while it is also aiming to unveil historically changing strategies for identity construction.

\section{Explanation of the methods of research and the research activity}

During the first stage of the research, the relevant literature of overseas Hungarian diaspora research is being processed in the form of a literature review, which is structured by focusing on elements effecting assimilation and identity maintenance. In the light of the topics, problems and connections that have arisen throughout the review, research-specific 
questions are being formulated and - in a manner typical of inductive research - the population to be sampled is being outlined more accurately.

In the sampling stage of the research, the legacy of diasporal Hungarians in libraries and archives is being sampled at the location(s) and individuals are being interviewed. The methods of sampling documents of libraries and archives are determined by the respective catalogs, the level of digitization and access regarding the location. I mainly plan to use boolean search techniques and pick the sample by defining a new search string, then I aim to narrow down the results through applying methods of source criticism. In case the level of computer-based cataloging is not advanced enough or the card indexes are likely to cover materials that are not available in the computer-based catalog, I will choose items manually from an address list, using random sampling after filtering and processing the content. The individual interviews will be structured by regions and small communities, and a cross-sectional study will be performed preceded by nonprobability, convenience sampling. The survey is constructed using closed-ended and open-ended questions; the questions will cover four primary dimensions and are divided into the same number of sections: the first dimension consists of questions regarding demographic data, the second dimension measures the strength of ethnic (Hungarian) identity, the third one examines the attitudes towards majority societies, while the fourth dimension concerns the knowledge and judgment of the homeland's national policy measures relevant to the diaspora. On textual level, we would like to identify formal and informal communities that are divided both in historical memory and in practice, patterns of group agency, shared goals, relations between groups, coping and emotional identification (both on the level of individuals and groups), as well as the relation between these and the individual agents. For documentational purposes, an interview log is being recorded and the locations are being marked on a Google Earth map, using color coding and data related to the respective locations.

Essentially, by using the samples collected from individual interviews' transcripts and the legacy in libraries and archives, a corpus is being established, which lists historical and practical experiences side by side; they are compared during the analysis and they inspect historically changing identity construction strategies. After collecting data, the samples chosen from the legacy in libraries and archives are being digitalized in a searchable form, the interviews also go through the same process. All of these data are being made open access. This has a dual aim: on the one hand, to perform software-aided analysis on it (using ATLAS or CATMA depending on the availability of the software), and on the other hand, to make our work traceable and easier to replicate, as well as to make the obtained results re-usable by others for future projects.

Within the discussion following the analysis, the results are being placed in a broader context, and attempts are being made to suggest decisions with national strategical significance and point out tasks to be solved that are relevant to the enhancement of the national identity of the diasporic Hungarians overseas. 


\section{Impact}

\section{The prospective results of the research}

\section{Direct results of the research}

The prospective results can be categorized into three groups: firstly, as an original innovation, we create a searchable, open-access database consisting of texts of credible historical sources and individual micro-narratives, containing the past and present assimilative and identity maintenance strategies of the Hungarian diaspora. Secondly, we obtain genuine research results that depict said local assimilative and identity maintenance strategies regarding their historical correspondences and their present state, they deepen our knowledge concerning the national identity of diasporic Hungarians, the methods and elements of their identity construction, as well as the factors that affect the relevant changes. Thirdly, based on the results, we will be able to formulate functional proposals regarding national policy, which can help the Hungarian government support the preservation of national identity in the diaspora communities more efficiently.

\section{Expected effect of the research in the Hungarian diaspora overseas}

Another result of the research that cannot be overlooked will be that diasporic Hungarians will receive positive feedback from their homeland as they will be contacted individually and they will get to know the objectives of the research and the organization being in charge of it. This will demonstrate that the relationship with residents of the homeland is active on a state level as well, and also that they (members of the diaspora) are important for Hungary and Hungarian locals are interested in the way diasporic Hungarians will retain their national identity and also the factors that might hamper this process.

\section{Usability of research results}

The results of the research firstly contribute to the national policy planning relevant to the diaspora as they make previously unavailable knowledge, information and correspondences available while providing all of this to decision-makers in a historical context. This way, they also can assist the preservation of the national-cultural identity and welfare of diasporic Hungarians, as well as the development or optimization of economical and cultural relations of the homeland. Secondly, the research will result in a database through which users can access texts that could serve as the bases of future research projects, so the usability of the results is not only temporary, but also potentially long-term. Thirdly, through the creation of the research material and its objectivization in English language articles or specialized studies, the program could gain significant international media coverage and its results could be introduced to the scientific community. 


\section{Implementation}

\section{Research Schedule}

August 1-30 2015: Creating the structured literature review. Contacting the embassy and local institutions that are significant in relation to the Hungarian diaspora (Hungarian parishes/congregations, Hungarian schools, associations, study groups, etc.). Integration, the establishment of trust, participating in local community programs.

September 1-October 30 2015: Gathering the contact details of potential individual interviewees, establishing contact, inquiring about the participation in the program, agreement upon times. Performing interviews, constant documentation and coding the texts for software analysis. After gathering data, writing an analysis in the form of a workshop study.

November 1-December 31 2015: Performing research in libraries and archives. Identifying/ visiting locations, processing catalogs, digitalizing results, writing an identity-centric analysis in the form of a workshop study. Reviewing current national policy measures relevant to the Hungarian diaspora and their legal status, formulating proposals for datadriven development.

\section{Funding program}

This proposal has been submitted to the State Secretariat for National Policy of the Prime Minister's Office, Hungary; in the framework of Mikes Kelemen Program. The proposal has been shortlisted and an oral presentation and discussion has taken place with the Evaluation Committee on the 28 July, 2015. The proposal did not receive funding and no reviewer comments were provided.

\section{Call}

Mikes Kelemen Program 2015 Call for Proposals

\section{References}

- $\quad$ Cohen R (2008) Global Diasporas. An introduction. 2nd. Routledge, London and New York, 219 pp. [In English]. [ISBN 978-0-203-92894-3]

- Safran W (1991) Diasporas in Modern Societies: Myths of Homeland and Return. Diaspora: A Journal of Transnational Studies 1 (1): 83-99. DOI: 10.1353/dsp.1991.0004 